\title{
Not a Cheap Investment: Estimating the Cost of the 2017 to 2018 Ophthalmology Residency Match to the Applicant and Program
}

\author{
Daniel B. Moore, MD ${ }^{1}$ \\ ${ }^{1}$ Department of Ophthalmology and Visual Sciences, University of \\ Kentucky, Lexington, Kentucky \\ J Acad Ophthalmol 2018;10:e158-e162.
}

\begin{abstract}
Address for correspondence Daniel B. Moore, MD, Department of Ophthalmology and Visual Sciences, University of Kentucky, 110 Conn Terrace, Suite 550, Lexington, KY 40508

(e-mail: daniel.b.moore@uky.edu).
\end{abstract}

\begin{abstract}
Keywords

- ophthalmology

- residency match

- residency interviews

- residency application

- cost

- medical student
\end{abstract}

Purpose To estimate the cost of the match process for all ophthalmology applicants and the departmental costs at the University of Kentucky during the 2017 to 2018 match cycle.

Design Financial analysis.

Methods Using the available national match statistics for the 2017 to 2018 ophthalmology residency match and the mean of all residency interview costs available in the literature, the estimated mean and total match costs were calculated for all applicants, including application fees and interviews. Program costs were estimated based on direct interview costs, lost productivity, and fixed costs.

Results Of 625 applicants, 475 matched into an ophthalmology residency position in 2017 to 2018 . The mean estimated cost was US $\$ 6,613$ for matched applicants, and all applicants spent US\$4,646,950 on the match in aggregate. Our department spent an estimated US\$179,327 over four interview days with 12 faculty volunteers, or an average of US $\$ 3,736$ per each of 48 interviewed applicants.

Conclusions and Relevance Matching into an ophthalmology residency position is expensive not only for the applicant but also the program. Reforms to the process would likely be beneficial to both parties.
In 2017, 18,261 students graduated from U.S. medical schools $^{1}$ with a mean debt of US\$190,694. ${ }^{2}$ Both of these figures are continuing to rise year over year, and educational debt remains a central concern in addressing physician workforce diversity in geographic location and specialty. ${ }^{3}$ Medical students have additionally raised concerns about the cost of the residency interview process, indicating that the expenses are overly burdensome and that financial considerations influence their decision to attend interviews. ${ }^{4}$

This past match cycle, 689 U.S. and international applicants competed for 475 ophthalmology residency positions. Over the past decade, the number of positions offered has slightly increased from 458 in 2009, whereas the number of applications has actually decreased from 767. Despite this, the competitiveness of the match, as measured by percent matching, has not changed. What has increased substantially, however, is the number of applications per applicant: from 41 in 2004, to 50 in 2009, and up to 73 and 69 for the average matched and unmatched applicants in 2018, respectively. Matched and unmatched applicants also attended an average of 12 and 4 interviews, respectively. ${ }^{5}$

Data regarding the financial burden of the match process for applicants are limited but suggest significant expense for this cost-conscious population..$^{3,6-15}$ The goal of this study is to provide a reasonable estimate of the cost associated with the received

September 7, 2018 accepted after revision October 11, 2018
DOI https://doi.org/ $10.1055 / \mathrm{s}-0038-1675846$. ISSN 2475-4757.
Copyright (c) 2018 by Thieme Medical Publishers, Inc., 333 Seventh Avenue, New York, NY 10001, USA. Tel: +1(212) 584-4662.
License terms

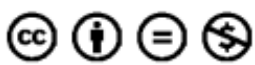


ophthalmology residency match process for both applicants and programs using available national and local data.

\section{Materials and Methods}

The numbers of registrants, participants, rank list submissions, and matched and unmatched applicants for the 2017 to 2018 ophthalmology residency match cycle were obtained from the publicly accessible Association of University Professors of Ophthalmology (AUPO) and San Francisco (SF) Match Summary Report. ${ }^{5}$ The mean number of applications and interviews for matched and unmatched applicants were also obtained using the same dataset. Application fees for the SF Match Residency Matching Services were used to determine the mean application cost for matched and unmatched applicants. ${ }^{16}$ Existing literature was used to estimate the applicant cost per interview ${ }^{3,6-15}$; the mean of these reports was used.

Program costs were calculated from interview costs for each of four half-day interview sessions at the University of Kentucky during the 2017 to 2018 ophthalmology residency match cycle. A total of 48 applicants were interviewed for four positions. Clinical productivity was based on the fiscal year 2017 to 2018 mean half-day collections and fixed overhead for the 12 faculties that participated in each of the interviews. Fixed costs were based upon the same faculty and fiscal year and included the sum of the Dean's overhead cost, faculty and personnel salaries and fringes covered by the department, and other fixed expenses.

All costs were in 2017 U.S. dollars and converted when necessary using the consumer price index data for urban consumers.

\section{Results}

There were a total of 735 registrants, 689 participants, and 625 rank lists submitted for 475 available positions in the 2017 to 2018 ophthalmology residency match. The mean number of applications was 73 for the 475 applicants that matched and 69 for the 150 that went unmatched. The application cost for the mean applicant was US\$1,665 and US\$1,525 for matched and unmatched applicants, respectively, for a total estimated application fee of US\$1,082,125 for the 625 applicants that submitted rank lists (-Table 1).

Eleven surveys were conducted between 2006 and 2016, providing estimates of applicant cost per residency interview, with a mean of US\$404 (range: US\$306-US\$522) (-Table 2). The mean number of interview invites was 12 and 4 for matched and unmatched ophthalmology applicants during the 2017 to 2018 match, respectively. Presuming applicants attended all invited interviews, the mean cost for interviews was US $\$ 4,848$ and US $\$ 1,616$, and the total cost of applications and interviews was US\$6,613 and US\$3,241, respectively. Based on these mean data, the total match cost for all 625 applicants was US\$4,646,950 (

Program costs are presented in -Table 3 . The estimated cost for each of the four interview dates was US\$44,832, with a total cost of US\$179,327 for the match cycle, and an average of US\$3,736 spent on each of 48 applicants interviewed.
Table 1 Estimated 2017 to 2018 match costs for ophthalmology residency applicants

\begin{tabular}{|l|l|l|l|}
\hline & $\begin{array}{l}\text { Mean } \\
\text { matched } \\
\text { applicant, } \\
\mathbf{N}=\mathbf{4 7 5}\end{array}$ & $\begin{array}{l}\text { Mean } \\
\text { unmatched } \\
\text { applicant, } \\
\mathbf{N}=150\end{array}$ & $\begin{array}{l}\text { Total cost } \\
\text { for all } \\
\text { applicants, } \\
N=625\end{array}$ \\
\hline $\begin{array}{l}\text { Number of } \\
\text { applications } \\
\text { submitted }\end{array}$ & 73 & 69 & US $\$ 1,082,125$ \\
\hline $\begin{array}{l}\text { Total } \\
\text { application } \\
\text { fees }\end{array}$ & US\$1,765 & US\$1,625 & \\
\hline $\begin{array}{l}\text { Number of } \\
\text { interviews }\end{array}$ & 12 & 4 & US $\$ 3,564,825$ \\
\hline $\begin{array}{l}\text { Cost for } \\
\text { interviews }\end{array}$ & US\$4,848 & US\$1,616 & US $\$ 4,646,950$ \\
\hline $\begin{array}{l}\text { Total } \\
\text { match } \\
\text { costs }\end{array}$ & US\$6,613 & US $\$ 3,241$ & \\
\hline
\end{tabular}

\section{Discussion}

The medical residency match is based upon a market algorithm designed by Alvin Roth, leading to a Nobel Prize in Economics in 2012 shared jointly with Lloyd Shapley for the "theory of stable allocations and the practice of market design." 17 Despite the accolade, the medical matching process is the only professional training organization currently using this system. ${ }^{18}$ Because of the competitive nature of the match, applicants are applying to an increasing number of programs. The costs associated with this process have the propensity to be detrimental to the most financially strained, with one pointed comment in an applicant survey stating: "This is the glass ceiling. It is set up to make economic minorities fail." 4 Furthermore, applicants from rural programs may have to travel longer distances and incur even greater costs. ${ }^{10}$ A survey of 2006 Urology resident applicants found that those attending northeastern medical schools had significantly lower interview costs than other regions of the country. ${ }^{6}$ This, in part, may be why ophthalmology applicants are significantly more likely to match in the same geographic region as their medical school. ${ }^{19}$ These findings raise concerns about not only the match process for the applicants but also the programs that seek to select the most desirable candidates from a diverse geographic pool.

This study and calculations provide further validation of the costs. The mean matched ophthalmology applicant spent an estimated US\$6,613 on the match, whereas the mean unmatched applicant spent roughly half that amount. Although it may initially be reassuring that unmatched applicants spent less, one reason that applicants are willing to spend, increasingly, so much on the match is the tremendous opportunity cost of going unmatched. The estimated total cost of US $\$ 4,646,950$ for all applicants that submitted rank lists are similar to prior studies of US\$3,228,556 for urology, ${ }^{10}$ US $\$ 3,358,584$ for otolaryngology, ${ }^{20}$ US $\$ 3,557,410$ for neurosurgery, ${ }^{9}$ and US $\$ 20,177,666$ for emergency 
Table 2 Mean estimated applicant cost per resident interview in the current literature

\begin{tabular}{|c|c|c|}
\hline Study population & $\begin{array}{l}\text { Response } \\
\text { rate (\%) }\end{array}$ & $\begin{array}{l}\text { Mean cost }{ }^{\mathrm{a}} \\
\text { (in U.S. dollars) }\end{array}$ \\
\hline All 468 urology applicants in $2006^{6}$ & 61 & $401^{\mathrm{b}}$ \\
\hline All 367 plastic surgery residency applicants in $2006^{7}$ & 38 & 522 \\
\hline All 194 applicants to a single plastic surgery residency program in $2012^{8}$ & 65 & 463 \\
\hline All 202 first year neurosurgery residents in $2015{\text { (2014 match cycle })^{9}}^{9}$ & 64 & 485 \\
\hline An estimated 525 applicants to 18 urology residency programs in $2014^{10}$ & 33 & 517 \\
\hline 1,091 applicants to 4 orthopaedic residency programs in $2015^{11}$ & 37 & 335 \\
\hline $\begin{array}{l}\text { All } 1,425 \text { applicants to emergency medicine that were members } \\
\text { of the emergency medicine resident association in } 2016^{3}\end{array}$ & 13 & 344 \\
\hline All 81 residency applicants to a single emergency medicine program in $2016^{12}$ & 81 & 331 \\
\hline All 195 applicants from the University of Kansas School of Medicine in $2016^{13}$ & 84 & 306 \\
\hline All 61 applicants from the University of South Dakota School of Medicine in $2016^{14}$ & 68 & 404 \\
\hline All 370 otolaryngology residency applicants in $2016^{15}$ & 49 & $340^{\mathrm{b}}$ \\
\hline Overall mean cost & & 404 \\
\hline
\end{tabular}

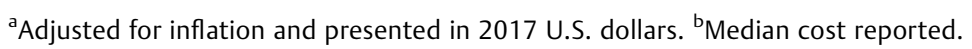

medicine ${ }^{3}$ applicants per match cycle. Similarly, we found that resident interviews produced a substantial cost to our department: US\$179,327 in total or US\$3,736 per applicant interviewed. A comparable estimation of program costs for resident interviews of a single plastic surgery residency that interviewed 53 applicants found the total cost was US $\$ 151,277$ and the cost per applicant was US\$2,854. ${ }^{21} \mathrm{~A}$ survey of 82 emergency medicine program directors estimated that the cost was US\$214,845 per program per year and US\$47,910,292 for all emergency medicine programs in an interview season. ${ }^{3}$

What changes could be made to potentially improve this process? Video conference interviews for ophthalmology

Table 3 Total estimated University of Kentucky Ophthalmology program costs for 2017 to 2018 residency interviews

\begin{tabular}{|l|l|}
\hline Category $^{\mathrm{a}}$ & $\begin{array}{l}\text { Cost } \\
\text { (in U.S. dollars) }\end{array}$ \\
\hline Meals $^{\mathrm{b}}$ & 4,655 \\
\hline Supplies & 528 \\
\hline Losses in faculty clinical productivity $^{\mathrm{c}}$ & 89,952 \\
\hline Losses in clinic fixed costs $^{\mathrm{d}}$ & 84,192 \\
\hline Total program costs per interview & 44,832 \\
\hline Total program costs per match cycle & 179,327 \\
\hline Cost per applicant Interviewed & 3,736 \\
\hline
\end{tabular}

anterviews were conducted over four separate half-day weekday sessions. A total of 12 faculties participated in each interview session and 48 applicants were interviewed. ${ }^{b}$ Include applicant reception with current residents, breakfast and lunch on the interview day, and a rank list dinner for faculty following the final interview. 'Mean individual faculty collections per half-day session multiplied by 12 faculties and 4 interview dates. ${ }^{\mathrm{d}}$ Mean faculty fixed costs per half-day session multiplied by 12 faculties and 4 interview dates. Fixed costs include the sum of the Dean's overhead, faculty and personnel salaries and fringes covered by the practice, and other fixed expenses. resident applications have been trialed at the University of Arizona, ${ }^{22}$ although there are some potential trade-offs with this approach. ${ }^{23}$ Particularly in large urban areas, programs can coordinate the scheduling of interview dates, as was done in Chicago for emergency medicine applicants with significant cost savings and a favorable applicant review. ${ }^{24}$ Specialty societies and other national organizations could negotiate special interview rates with national airlines and hotel chains, and grassroots efforts by medical schools and residency programs may provide more affordable housing and travel options for applicants. ${ }^{3} \mathrm{~A}$ recent publication regarding the surgical fellowship match suggested using a variation on the deferred acceptance matching algorithm currently used to have an "interview match" that precedes the standard fellowship match. After applications have been submitted and reviewed, both applicants and programs would create rank lists to fill a more limited number of interview spots. Therefore, both parties theoretically interview preferentially with fewer required interviews. ${ }^{25}$

Another option that would benefit both applicants and programs is to limit the number of applications an individual can submit. Applying the game theory model of prisoner's dilemma to the urology match, Weissbart et $\mathrm{al}^{26}$ determined that not only is allowing unlimited applications inefficient, but it is also financially burdensome for both applicants and programs. In their estimation, applicants could collectively save up to US\$613,000 and program directors individually 1,639 minutes per match cycle with an application limit of 30. Using similar logic, an application limit could be set for the ophthalmology residency match. Based on match data from the past 2 years, the number of interview invites does not increase significantly for applicants beyond 40 applications, 5,27 and such a cap would result in an estimated savings of US\$825,875 for the 625 applicants that submitted rank lists this past match cycle. Using the previous estimate of 5 minutes spent reviewing each application, ${ }^{26}$ the mean of 
114 program directors participating in the match would have reviewed 176 fewer applications and saved 878 minutes or 14.6 hours of time with this limit. However, these potential savings for applicants would have to come at the expense of the sponsoring organization and beneficiaries. As an example, using the Electronic Residency Application Services (ERAS) fee formula, 2015 fees for all student ERAS applications was US\$72 million, representing approximately $40 \%$ of the Association of American Medical Colleges operating revenue for that year. ${ }^{3}$ Using the tiered distribution fee schedule from SF Match, ${ }^{16}$ an application limit of 40 would cost each applicant US $\$ 410$, for a total of US $\$ 256,250$ for all 625 applicants in 2017 to 2018. With an estimated US $\$ 1,082,125$ in application fees, this limit would reduce revenue by approximately $80 \%$. It should be emphasized this is an estimate based on mean application data, and while exact financial analysis is not possible, the loss to SF Match and other beneficiaries would be substantial if compensatory changes were not made in the fee structure.

A restriction to the number of applications per applicant poses several reasonable potential objections. For instance, applicants may potentially be applying to an increasing number of programs not to improve the probability of matching but due to interest in a larger and broader range of programs. Other concerns include the possibility that applying to an unlimited number of programs improves applicants' happiness and sense of control or that an application limit would decrease competition. Weissbart et $\mathrm{al}^{26}$ presents a thorough analysis and refutation of these and other objections. Regardless of where an application limit is set, applicants would need sufficient information to make educated decisions on where to selectively apply. Accordingly, programs would need to provide information about screening criteria and additional standards when reviewing applications to allow applicants the opportunity to strategically apply to a restricted number of programs.

There are several important limitations to this study. The match dataset presents mean statistics; therefore, precise measurements are not possible. The surveys used to estimate interview costs have multiple inherent biases and are not specific to ophthalmology. While we plan to obtain this information in the future, it is unlikely to alter the underlying conclusion of this and other similar studies: the interview process is expensive. In fact, this analysis likely underestimates to true cost of matching for two reasons. First, the cost of away rotations is not included. There is one limited survey including ophthalmology that found applicants completed a mean of 1.9 away rotations at a cost of US $\$ 990$ per rotation. ${ }^{28}$ Another study estimated a mean cost of US $\$ 1,100$ for emergency medicine applicants. ${ }^{12}$ Second, these figures do not account for the separate cost to apply and interview for preliminary year positions. There are no existing data to estimate these costs, although the independent matching process may soon be changing. ${ }^{29}$ This analysis presumed that applicants attended all invited interviews. While this is not likely the case, the mean of 12 interview invites is similar to the overall average of 10.91 ranked programs for all 27,424 successfully matched appli- cants in the 2018 National Resident Matching Program. ${ }^{30}$ Lastly, the program costs are specific to our institution and the interview year. The number of interview dates offered, faculty involvement, and weekday versus weekend dates, among other factors, vary widely. Collectively, these data compel a broader examination of the costs associated with the match process.

The AUPO and SF Match should be commended for providing match statistics to the public for evaluation; these data continue to be beneficial for applicants and programs alike. The trends in recent years, however, coupled with cost analyses demonstrate the need for change. It is time to reconsider the ophthalmology residency application and interview process, primarily to aid not only our applicants and future colleagues but also the programs themselves.

Conflict of Interest

None.

\section{References}

1 Barzansky B, Etzel SI. Medical schools in the United States, 20162017. JAMA 2017;318(23):2360-2367

2 Association of American Medical Colleges. Medical Student Education: Debt, Costs, and Loan Repayment Fact Card. http://members.aamc.org/iweb/upload/2017\%20Debt\%20Fact\%20Card.pdf. Accessed August 2018

3 Van Dermark JT, Wald DA, Corker JR, Reid DG. Financial implications of the emergency medicine interview process. AEM Educ Train 2017;1(01):60-69

4 Association of American Medical Colleges. Cost of Applying to Residency Questionnaire Report. 2015. https://www.aamc.org/ download/430902/data/costofapplyingtoresidency.pdf. Accessed August 2018

5 Association of University Professors of Ophthalmology. SFMatch. Ophthalmology Residency Match Summary Report 2018. https:// www.sfmatch.org/PDFFilesDisplay/Ophthalmology_Residency_Stats_2018.pdf. Accessed August 2018

6 Kerfoot BP, Asher KP, McCullough DL. Financial and educational costs of the residency interview process for urology applicants. Urology 2008;71(06):990-994

7 Rogers CR, Gutowski KA, Munoz-Del Rio A, et al. Integrated plastic surgery residency applicant survey: characteristics of successful applicants and feedback about the interview process. Plast Reconstr Surg 2009;123(05):1607-1617

8 Claiborne JR, Crantford JC, Swett KR, David LR. The plastic surgery match: predicting success and improving the process. Ann Plast Surg 2013;70(06):698-703

9 Agarwal N, Choi PA, Okonkwo DO, Barrow DL, Friedlander RM. Financial burden associated with the residency match in neurological surgery. J Neurosurg 2017;126(01):184-190

10 Nikonow TN, Lyon TD, Jackman SV, Averch TD. Survey of applicant experience and cost in the urology match: opportunities for reform. J Urol 2015;194(04):1063-1067

11 Camp CL, Sousa PL, Hanssen AD, et al. The cost of getting into orthopedic residency: analysis of applicant demographics, expenditures, and the value of away rotations. J Surg Ed 2016; 73(05):886-891

12 Blackshaw AM, Watson SC, Bush JS. The cost and burden of the residency match in emergency medicine. West J Emerg Med 2017;18(01):169-173

13 Walling A, Nilsen K, Callaway P, et al. Student expenses in residency interviewing. Kans J Med 2017;10(03):1-15 
14 Chang PS, Rezkalla J, Beard M. An analysis of the financial burden associated with the residency match at the University of South Dakota Sanford School of Medicine. S D Med 2018;71 (02):66-69

15 Cabrera-Muffly C, Chang CWD, Puscas L. Current interview trail metrics in the otolaryngology match. Otolaryngol Head Neck Surg 2017;156(06):1097-1103

16 SF Match Residency and Fellowship Matching Services. Central Application Services Application and Distribution Fees. https:// sfmatch.org/SpecialtyInsideAll.aspx?id=6\&typ=2\&name=0phthalmology\#. Accessed August 2018

17 The Nobel Prize Organization. The Sveriges Riksbank Prize in Economic Sciences in Memory of Alfred Nobel 2012. https://www. nobelprize.org/prizes/economics/2012/summary. Accessed August 2018

18 Black CC. Examination of the residency interview process for academic pathology departments: how to make the most of a resourceheavy process. Acad Pathol 2016;3(03):2374289515623551

19 Loh AR, Joseph D, Keenan JD, Lietman TM, Naseri A. Predictors of matching in an ophthalmology residency program. Ophthalmology 2013;120(04):865-870

20 Polacco MA, Lally J, Walls A, Harrold LR, Malekzadeh S, Chen EY. Digging into debt: the financial burden associated with the otolaryngology match. Otolaryngol Head Neck Surg 2017;156 (06):1091-1096

21 Susarla SM, Swanson EW, Slezak S, Lifchez SD, Redett RJ. The perception and costs of the interview process for plastic surgery residency programs: can the process be streamlined? Plast Reconstr Surg 2017;139(01):302e-309e
22 Pasadhika S, Altenbernd T, Ober RR, Harvey EM, Miller JM. Residency interview video conferencing. Ophthalmology 2012; 119(02):426-426.e5

23 Shah SK, Arora S, Skipper B, Kalishman S, Timm TC, Smith AY. Randomized evaluation of a web based interview process for urology resident selection. J Urol 2012;187(04):1380-1384

24 Shappell E, Fant A, Schnapp B, et al. A novel collaboration to reduce the travel-related cost of residency interviewing. West J Emerg Med 2017;18(03):539-543

25 Melcher ML, Ashlagi I, Wapnir I. Matching for fellowship interviews. JAMA 2018;320(16):1639-1640

26 Weissbart SJ, Hall SJ, Fultz BR, Stock JA. The urology match as a prisoner's dilemma: a game theory perspective. Urology 2013;82 (04):791-797

27 Association of University Professors of Ophthalmology. SFMatch. Ophthalmology Residency Match Summary Report 2017. https:// www.sfmatch.org/PDFFilesDisplay/Ophthalmology_Residency_Stats_2017.pdf. Accessed August 2018

28 Winterton M, Ahn J, Bernstein J. The prevalence and cost of medical student visiting rotations. BMC Med Educ 2016;16(01):291

29 ACGME Program Requirements for Graduate Medical Education in Ophthalmology. https://www.acgme.org/Portals/0/PFAssets/ReviewandComment/240_Ophthalmology_2018-08-06_R\&C.pdf. Accessed August 2018

30 National Resident Matching Program. Impact on Length of Rank Order List on Match Results: 2002-2018 Main Residency Match. http://www.nrmp.org/wp-content/uploads/2018/03/Impact-ofLength-of-Rank-Order-List-on-Match-Results-2018-Main-Match. pdf. Accessed August 2018 